\title{
A TERRA E OS SEUS FILHOS MONSTRUOSOS: A GESTÃO DA CIDADE SOB OS TRÓPICOS
}

\author{
Ana Luiza Carvalho da Rocha
}

\section{Introdução}

A partir de reflexões em torno das imagens do bestiário, do grotesco e do monstruosos para o nascimento da "civilização urbana" no corpo de uma América barroca, este ensaio tratara da tópica da desordem e da assimetria na consecução de projetos de democracia participativa para os arranjos da vida social no interior das cidades brasileiras, a partir da experiência do Orçamento Participativo em Porto Alegre.

\section{A intenção}

Este assunto assenta-se numa reflexão modesta sobre os processos de participação social que, hoje, orientam as políticas urbanas no sentido de uma "cultura cidadã" como dispositivo orientador do complexo civilizacional das cidades no Brasil. Em especial este tema se destaca tendo como pano de fundo as praticas discursivas sobre os temas mais que mediatizado da crise, do medo e da violência urbana. Por um lado, trago como referencia duas obras importantes sobre as cidades brasileiras quais sejam o trabalho de Tereza Caldeira em torno da cidade de muros e da construção de uma democracia disjuntiva em nosso país e o de sobre Yves Wancquart sobre a criminalizaçao da pobreza nas grandes metrópoles contemporâneas para o caso brasileiro. Por outro, apoio-me em algumas das conclusões de minha tese de doutorado, intitulada $O$ santuário da desordem, a arte de saber-viver dos doces bárbaros sob os Tristes Trópicos, no que diz respeito a três aspectos sob o ponto de vista dos estudos do imaginário, através da obra de G. Durand, As estruturas antropológicas do imaginário:

1) a dominância mítica das paisagens noturnas e dos figurinos do Bestiário que orienta a dialética das imagens infernais ou paradisíacas nos mitos de fundação das cidades no sul do Brasil desde a perspectiva de uma geografia fantástica, e onde o complexo civilizacional urbano irá concentrar as aspirações primevas do Herói civilizador diante da matéria terrestre dos Trópicos, no período da conquista e colonização;

2) a dominância da simbólica do terror e da morte que regulam as relações do Herói civilizador com a matéria terrestre nos Trópicos através do suplicio a ela aplicado, o qual 
se torna a um dos gestos orientadores da construção de uma civilização urbana no sul do Brasil como parte do processo de domesticação da alma barbara do seu povo e, finalmente,

3) a dominância simbólica das aspirações soberanas e ascencionais que configuram as imagens do colonizador/conquistador em face dos perigos de sua queda moral no interior nos Trópicos.

Para o leitor é importante o esclarecimento de que estou aqui polemizando duas perspectivas epistemológicas que tratam do fenômeno social e suas relações como os fenômenos de ordem temporal, isto é, a da teoria da ação e a teoria da interpretação. A primeira, e penso ser esta que se coloca como hegemonia para o caso das analises das experiencias de gestão participativa nas cidades brasileiras, adota a perspectiva da razão prática, ao privilegiar a racionalidade e os fluxos de consciência e intencionalidade assim como a prática dos atores sociais no interior da vida urbana, sendo tais dimensões aquelas que, em última instancia, dotam os laços sociais de tal ou qual feição. Sob este ângulo, a sucessão temporal dos acontecimentos e fatos sociais na cidade não possuem nenhuma dimensão teleológica (de intriga), ao contrário, a vida urbana e suas formas de vida social tornam-se a expressão exteriorizante e objetivista de uma ordem econômico-produtivo num determinado espaço, tratados desde aí como fatos brutos.

A outra perspectiva, que se polemiza com a anterior, aponta para uma hermenêutica dos fenômenos sociais que configuram as formas de vida urbana nas cidades brasileiras, irredutíveis a uma razão de ordem econômica, jamais prisioneira da cronologia de fatos exteriores (monumentais ou não) à vida vivida por seus habitantes. A cidade se conforma, assim, como uma unidade teleológica, tendo em vista que o viver urbano é plural, comportando diferentes dimensões espaço-temporais irredutíveis aos fluxos de consciência de seus habitantes, nem a uma consciência histórica para alem do vivido de seus habitantes, nem mesmo "como rastro da Razão na história", nos termos de P. Ricoeur"

Nesta apresentação, portanto, a cidade torna-se um mundo tecido desde os laços simbólicos entre seus habitante, laços urdidos pelos atos de consciência de seus moradores, segundo suas distintas tradições tanto quanto pela consciência homogeneizadora das temporalidades históricas e progressistas, mas acima de tudo urdidos desde o caráter simbólico das ações sociais, o qual nos conduz a aceitação do papel fundamental da vida dos símbolos na construção das cidades moderno-contemporâneas como espaço de

${ }^{1}$ Cf. P. Ricoeur, Tempo e Narrativa. Vol. III. São Paulo, Papirus, 1994, p. 348. 
atualização de utopias e distopias e, em decorrência, e da importância dos mitos na configuração da vida cotidiana de suas comunidade urbanas.

A partir destes eixos norteadores de contribuições, ressaltaria, portanto, a importância que assumem, no presente, as imagens ancestrais do grotesco e do monstruoso, para descrever as escalas distintas que separam as formas tradicionais de participação dos grupos sociais e de suas formas de negociação na vida cotidiana dos processos participativos formais e abstratos na organização da vida urbana na conformação das cidades brasileiras. Seria tentada a situar ambos os processos de participação em distintos registros do imaginário urbano das cidades tropicais(toma-se aqui o caso de Porto Alegre), associados as racionalizações de mitos latentes e manifestos que se polemizam entre si, as quais irrompem no campo mítico do ideário do individualismo modernos e seus postulados como modulador da ação da vida social nas grandes metrópoles contemporâneas.

Trago aqui como referencia o caso da cidade de Porto Alegre, capital do Estado do Rio Grande do Sul, cidade reconhecida nacional e internacional por adotar o modelo de democracia participativa como experiência de gestão da vida metropolitana. A experiência do Orçamento participativo $(\mathrm{OP})^{2}$, modalidade de gestão que pretende, pelo viés da participação popular nas políticas publicas dos poderes municipais corrigir distorções e assimetrias provocadas pelo modelo econômico neo-liberal adotado no país, e que tende a excluir as populações mais pobres do direito aos benefícios que a cidade e a vida urbana se propõe oferecer.

Diante desta empreitada valho-me, em particular, dos conceitos de conflito e de sociação em G. Simmel (2006) e de duração em G. Bachelard (1989) na tentativa de promover, desde a retórica do progresso, a compreensão das distorções (o desnivelamento entre a imagem e o conceito de cidadania) que o modelo de gestão democráticoparticipativa e redistributiva ${ }^{3}$ dos usos dos territórios da vida urbana (em geral, infraestrutura e serviços públicos) passa a sofrer ao longo de sua adoção na vida cotidiana das camadas populares em Porto Alegre.

\footnotetext{
${ }^{2}$ O OP trata-se da forma de democracia participativa mais difundida no Brasil a partir da emergência de políticas participativas no país resultado (1) das experiências de participação popular ocorridas no Brasil entre os anos 70 e 80 - uma delas em Pelotas de 84-86; (2) do aumento de renda dos municípios em razão da Constituição de 88, a partir da reforma fiscal nas cidades brasileiras (fins da década de 80); (3) o aumento das prefeituras com gestão de esquerda, em particular do PT ( anos 90)

${ }^{3} \mathrm{O}$ caráter distributivo do OP é evidenciado por todos os que abordam esta forma de gestão, na medida em que ela pretende que "os usos da riqueza e do excedente social sejam debatidos e decididos por meio de processo democrático” ( Marqueti \& Campos, 2008:17)
} 
O desafio é pensar o modelo de gestão democrático-participativa e redistributiva a partir da logica antagonista(mas nem sempre polarizada) que reúne, em Porto Alegre, no plano do imaginário, a retorica do progresso nas ultimas décadas do séc. $\mathrm{XX}$ ao mito fundacional do atraso e do fracasso para a instalação da civilização urbana nos Trópicos, este ultimo potencialmente oculto e encoberto. Obviamente, que um tal fenômeno na ordem do simbólico provoca efeitos no plano da condução dos projetos sociais de redemocratização das ações dos poderes públicos da sociedade brasileira, e no seu interior, para o complexo civilizacional de suas grandes metropoles.

Refiro-me aqui, ao retorno, nas praticas discursivas ilustradas de técnicos e intelectuais, das imagens ancestrais da desordem, da degradação, do monstruoso e da queda moral para determinados territórios de vida de seu corpo coletivo (bairros e áreas marginais e marginalizadas) tanto quanto para aqueles que neles habitam, geralmente populações pobres (denominados de setores sociais de baixa renda), em sua maioria negros e pardos, migrantes e desempregados.

\section{A perspectiva do direito a cidade como um enredo, e não como destino.}

Adoto como chave interpretativa o ponto de vista da cidade como objeto temporal. Neste contexto, considero que a cidade e seus arranjos da vida social no contexto das atuais modernas sociedades complexas latino-americanas devem ser pensados desde a perspectiva das durações de instantes descontínuos que orientam a experiência humana de seus habitantes, os quais alem de serem atores e autores, também assumem o lugar de narradores da vida urbana.

Nas cidades moderno-contemporâneas são inúmeras e distintas as tradições narrativas segundo as quais a vida urbana é narrada, gerando tais narrativas determinados sistemas simbólicos que reúnem seus habitantes a determinados territórios de identidade e pertencimentos. Por outro lado, no contexto destas cidades tais identidades e pertencimentos transformam-se ao longo do tempo no interior de uma mesmo território. Falar; assim, do direito a cidade abdicar de uma perspectiva de racionalidade redutora na compreensão (e não explicação) das ações dos seus habitantes, é falar, portanto, dos múltiplos e tensionais sistemas de representações simbólicas associados a cidade na contemporaneidade, e que permanece escondida na historia de suas formas urbanas.

Portanto os discursos e as praticas em torno dos usos do espaço publico nas modernas sociedades complexas e, em especial, para o caso do complexo civilizacional urbano na América barroca, caso brasileiro, aponta não apenas para a heterogeneidade da 
construção simbólica do viver as cidades segundo a trajetória e os itinerários de seus grupos, mas a presença da diversidade no interior do próprio recorte moderno de cidadania.

A busca de um consenso para a vida urbana abarca, portanto, esta experiência temporal cuja composição é descontinua e heterogênea. E é precisamente neste contexto que se torna fundamental se refletir sobre as motivações simbólicas que orienta, o agenciamento das imagens do monstruoso e do grotesco pelo discurso ilustrado (técnico e cientificista) para compreender as "imperfeições" ou "desvirtuamentos" decorrentes da aplicação dos conteúdos formais da participação social na gestão das políticas urbanas, no caso de Porto Alegre. Esta incapacidade em atingir plenamente a harmonia ideal do progresso ocidental moderno, por vezes, é apontada como sendo o resultado de uma "doença" crônica que corrói as formas de vida social nas cidades brasileiras contemporâneas, mas que vem desde o nascimento da própria sociedade brasileira, de suas instituições políticas, sociais e culturais.

O desafio será, assim, pensar como tais imagens da deformidade como algo que "contamina" e "corrói" o corpo coletivo nas grandes cidades podem ser interpretadas como pertencentes a dominantes míticas onde a figura do Heroi solar é convocada a transformar tais formas coletivas de se habitar os espaços e territórios urbanos nas cidades brasileiras que não se encaixam nos padrões ético-morais veiculados pelos processos participativos formais. Formas diversas de habitar, trabalhar, apropriar-se e viver a cidade que afastandose do tempo finalista do mito do progresso retornam as narrativas fundacionais do Estadonação no Brasil - tais como a da mistura das raças e da degradação ético moral do homem brasileiro assim como de seus derivados, as imagens da corrupção, do terror; do abuso de poder e da violência - num apelo, nem sempre explicito, às "lembranças" das formas de vida coletiva no pais que remontam as formas de ocupação dos espaços públicos das cidades desde a colônia, passando pelas cidades imperiais até estas atingirem sua feição democrática e republicana.

Em termos de uma tópica sociológica, se a logica das formas de participação social na vida cotidiana desencadeia no interior de uma comunidade urbana arranjos sociais heterogeneizantes associados a regimes de pensar a cidade desde o sinergia (sintetico) entre as diversas formas de expressão da vida social que ela contempla, por seu turno, a logica da participação social oriunda das modalidades formais de representação a ela se opõe ao professar um regime de pensamento homogeneizante para a organização de seu corpo coletivo, seja pelo excesso da diferença, na tentativa de criar uma alteridade na 
identidade de uma comunidade (esquizomorfo), seja pela sua negação ou ausência (mistico). ${ }^{4}$

De uma forma ou outra, a filiação cega aos postulados da Razão como orientadores de tais arranjos acabam por produzir uma ação igualmente conquistadora, polemica e agressiva com relação a matéria "impura" das formas da vida coletiva se expressar no seu interior, a partir de arranjos "espúrios" até mesmo entre os distintos grupos e segmentos sociais (pobre e ricos, brancos e negros, homens e mulheres, adultos e crianças, velhos e jovens, etc.)

Aponto aqui para os laços complexos que formam um complexo civilizacional urbano no Brasil, e que reúne, a um só tempo, a realidade física de uma determinada forma ocupação territorial e a realidade social que a configura como comunidade de destino, e mais ainda, ressalto aqui os vínculos densos e espessos, em suas diversas camadas, que ambas as realidades criam os sistemas simbólicos através dos quais os habitantes de um território atribuem sentido as suas vidas (além, obviamente de tais sistemas simbólicos entre si. Operar com a idéia bachelardiana da dialética da duração representa, neste ensaio, portanto, um esforço no sentido de compreender a vibração das figuras arcaicas do "disforme" e do "monstruoso" como imagens imemoriais do nascimento do conjunto civilizacional das cidades brasileiras no interior dos arranjos sociais "modernos", veiculados pelos projetos de democracia participativa para seus habitantes.

Operar no plano de uma etnografia da duração para os estudos do imaginário traz como desafio se pensar a cidade moderno-contemporânea como objeto de analise, em níveis distintos, ou seja, dos processos de potencialização e atualização de constantes socioculturais através dos quais podemos pensar as composições entre as forças centrípetas (homogeneizadoras) e as forças centrifugas (heterogeneizadoras) que orientam a singularidade das suas formas de expressão da vida coletiva. A etnografia da duração significa igualmente a possibilidade de se refletir sobre as formas possíveis dos arranjos da vida social nas cidades brasileiras desde os princípios da justiça e da igualdade democrática, sem fazê-los vitima de um pensamento único, e onde cada cidadão (ou o “cidadão comum", e me pergunto se haveria outro?) estaria engajado na sinergia das ordens sociais que fundam uma cidade, e desde aí desafiado a se posicionar em torno dos

\footnotetext{
${ }^{4}$ A'propósito ver G. DURAND, « Le social et le mythique : pour une topique sociologique », Cahiers Internationaux de Sociologie, vol. LXX.
} 
benefícios e prejuízos que aporta para o coletivo da Cidade, aceitando-o desde a dimensão mítica que cerca sua existência social.

\section{A intriga}

O Orçamento Participativo tem sido apontado como um novo princípio éticopolítico para a organização dos arranjos da vida social nas grandes capitais do Brasil, ainda que tenha se centrado na dimensão formal, legal e jurídica dos processos participativos na condução de uma política urbana, relacionados em sua grande maioria ao acesso dos setores mais pobres dos grandes centros urbanos (os ditos "cidadãos comuns"5) a infraestrutura urbana, um dos pontos mais cruciais apontados para o seu direito a cidade.

Fora de um discurso finalista sobre a configuração de uma gestão democrática participativa o conjunto civilizacional urbano no Brasil, as distensões temporais que acompanham a pratica desta experiência como um modus vivendi da comunidade urbana de Porto Alegre não encontram espaço para reflexão. Geralmente opondo "vizinhos" a cidadãos", os processos de negociação que acompanham a instauração de uma gestão democrática para a cidade tendem a ser interpretados desde duas perspectivas distintas e, por vezes, complementares: 1) a perspectiva clássica de um relato histórico que interpreta o processo de implantação da OP desde as modalidades simbólicas de controle do tempo nas quais as descontinuidades revelam uma transformação nas formas de vida dos grupos populares na cidade (mito histórico) e 2) a perspectiva ortodoxa do mito do progresso cuja retorica interpreta este mesmo fenômeno a partir de uma perspectiva de avaliação moral de tais transformações, vendo nelas uma evolução no tempo.

Em ambos os casos, admite-se a importância que o estudo de tais analises representam para o estudo dos mitos e dos símbolos como componentes centrais de compreensão da vida social. Em ambos os casos podemos observar nas idéias que inspiram a OP ( a imaginação de uma Cidade outra, de onde se desprendem as imagens arcaicas do paraíso terrestre, cidade harmoniosa e equilibrada) a dimensão mítica de uma utopia, assim como o foram outras propostas de organização da vida social nas grandes cidades brasileiras, seja pautados por movimentos milenaristas, seja por ideologias revolucionarias.

\footnotetext{
${ }^{5}$ Inúmeros autores reconhecem que os setores reconhecidos como vulneráveis no interior da categoria cidadãos comuns, usualmente denominados de setores vulneráveis ou setores de baixa renda., tais como negros, jovens, mulheres, gays, lésbicas, bissexuais e transgêneros (GLBT), idosos, indígenas e imigrantes (Marqueti \& Campos, 2008: 22.) tem fraquíssima participação nos OP.
} 
Portanto, desde o tema do $\mathrm{OP}^{6}$, trata-se de pensar as tensões de uma logica antagonista entre, por um lado, o principio vital de agregação dos laços sociais no interior das cidades brasileiras, complexo em suas descontinuidades, fragmentações e heterogeneidades dadas nas negociações vividas na ordem do cotidiano (geralmente encobertos, ocultos e, por isto mesmo, relegados), e, por outro, a racionalidade da dimensão formal de vínculos sociais ${ }^{7}$, considerados desde o "processo de agregação de preferências para a tomada de decisões" sobre os usos coletivo (porque "populares") de certos territórios da vida urbana, nos termos da gestão democracia participativa proposta. ${ }^{8}$

Disjunções e polarizações que adquirem vulto no instante em que processos participativos com base em espaços públicos de representação formal emergem no interior dos territórios de importantes centros urbanos no Brasil e polemizam-se, ao longo do tempo, com formas arcaicas de sociação onde os lugares públicos ligados a vida cotidiana que continuam fazendo sentido para os segmentos mais pobres de sua população. ${ }^{9} \mathrm{O}$ OP se apresenta, então, como processo que conduziria ao empoderamento dos grupos populares no interior da política publica municipal, através da gestão participativa de seu processo orçamentário: preparação das políticas publicas, adoção, execução e controle no sentido de eliminar distorções, desigualdades e assimetrias no uso dos recursos públicos. ${ }^{10}$

Atualizando o imaginário dos espaços públicos das cidades da Grécia antiga (onde a condição de pobreza não excluía ninguém do acesso à polis, ainda que existisse um vinculo grande entre terra e cidadania) no âmbito da bacia semântica ${ }^{11}$ da cultura ocidental moderna, o OP assume a dimensão mítica de uma ágora e o cortejo de símbolos que

\footnotetext{
${ }^{6}$ Marqueti \& Campos,(2008: 19-20) mostram que de 1997 a 2004, 223 cidades brasileiras adotaram o OP como modelo de gestão da vida urbana,, sendo que $85,3 \%$ destes municípios mantiveram esta modalidade na gestão seguinte. Houve igualmente um aumento da população em cidades com OP, de 14,5 milhões na gestão de 1997-200 para 36,7 milhões de 2001-2004, ou seja, passando de $17,5 \%$ para $43,4 \%$ da população domiciliada em grandes cidades (em 2000 era, 84,5 milhões de pessoas que residiam em cidades).

${ }^{7}$ A proposito ver P. Ricoeur La Structure symbolique de l'action sociale : actes de la 14ème CISR, Lille,

1977, p. 39-41 e as distinções que o autor constrói para o caso da ação social entre o simbolismo constituinte e o simbolismo representativo.

${ }^{8}$ C. Marqueti \& Campos,(2008: 22) o participante típico nas assembléias do OP são mulheres na condição de "chefes de família", com pouca escolaridade e renda, e com filhos, o que contrasta com os conselheiros e delegados que são em sua maioria homens, com maior escolaridade e renda. Por outro lado, "as assembléias regionais atraem participantes mais pobres do que as assembléias temáticas".

${ }^{9}$ Segundo, trata-se de um processo participativo, por oposição ao modelo "elitista" envolvendo diferentes etapas de tomadas de decisões, cujas características são: "participação efetiva - indivíduos possuem igualdade de condições para expressar suas preferências"; "igualdade ao votar no estágio decisório - os votos são contados com pesos iguais no estágio final"; "melhorar o entendimento - os indivíduos devem ter igual oportunidade para aprender sobe as escolhas a serem realizadas"; "controle da agenda - os indivíduos devem ter o controle sobre as questões que serão decididas pelo processo democrático" e, finalmente, "inclusão dos adultos - todos os adultos devem possuir plenos direitos de cidadãos, que os quatro critérios acima implicam. ${ }^{10} \mathrm{Cf}$. Sergio Baierle, Lutas urbanas em Porto Alegre, entre revolução política e transformismo, Porto Alegre, Fundação Ford /ONG Cidade, 2007 
veicula a imagem do espaço publico, no sentido abstrato, o da circulação da palavra, das discussões e das leis, para o caso da construção da democracia nas cidades ocidentais moderno-contemporâneas. Não se pode esquecer que o $\mathrm{OP}$ e suas instancias de participação "popular" tomam a forma de espaços de debate e do uso da razão, de negociação do poder, geralmente de caráter deliberativo, aos quais se associam uma variedade de espaços decisórios: iniciativas, referendo, plebiscito e o town meeting (Marquetti, 2008: 32).

Para sustentar o que venho afirmando até o momento, vale a pena pensar com mais vagar nas constelações de imagens do espaço publico que inspira o OP e suas formas de sociação para o caso das institucionalização de modalidades democráticas de gestão participativa no caso do Brasil, seja em sua pretensão de ser o principio estruturante institucionalizado das formas de vida urbana, seja como reflexo das praticas sociais, ou ainda, seja através da construção de espaços públicos territorializados .

Neste ponto, aproximo as imagens incarnadas pelo OP e por suas arenas politicas no imaginário urbano porto-alegrense daquelas de um espaço abstrato de circulação da palavra - fórum, foyer -, de forte dimensão critica. Na atualização de tais imagens míticas da ágora grega (distorcida, em boa parte, segundo V. Azoulay, pela disseminação das teses habermasianas ${ }^{12}$ no pensamento de esquerda) o OP em Porto Alegre veicula a imagem de uma cidade composta de espaços organizados e hierarquizados entre si, e através dos quais toda uma comunidade urbana atribui forma a sua vida politica, até mesmo as suas formas não institucionalizadas. Tais imagens veiculadas pelo OP se polemizam com as imagens da vida publica nas cidades brasileiras, tomadas geralmente como espaços de manipulações grosseiras, à margem do sistema democrático, e onde a palavra politica se torna apenas simples comunicação, despolitizada e/ou monumentalizada, simbolo da dominação das elites. Ou, mais recentemente como imaginam alguns, em suas teses decadentistas, simbolo de uma nova forma de dominação dos poderosos a medida que afastam a OP dos

\footnotetext{
${ }^{12}$ Segundo Vincent Azoulay, L'espace public: un concept opératoire en histoire grecque?In: P.Boucheron et N. OFFENSTADT (éd.), L'espace public des historiens .Paris, Complexes, 2008., o conceito de espaço publico na Grécia antiga esta longe de ser reduzido a um lugar ou a uma série de lugares públicos articulados entre si, ao contrario ele aparece entre os gregos como um princípio, o da publicidade, mais especificamente, a das leis. Ou seja, o espaço publico é em definitivo o território onde a cidade da conhecimento de seus leis, onde ela faz delas publicidade, tanto no sentido daquilo que pertence a comunidade quanto a qualidade daquilo que é tornado publico. Segundo aponta este autor é usual aqueles que se valem do ideário grego da ágora esquecerem que o conceito de publico na Grécia abarcava também os espaços intersticiais, não institucionalizados, que geralmente se desenvolviam as margens do seu sistema democrático e alguns à margem da própria cidade, em confronto com a tirania da maioria instaurada pelas oligarquias locais. Neste sentido, Vincent Azoulay alerta que na Grécia antiga assistimos mais a uma luta de legitimidade entre formas distintas de "espaço público" e onde o espaço publico democrático não é forçosamente aquele que se declara oprimido.
} 
segmentos populares das deliberações dos negócios da cidade, e o assujeitam as perversões de políticos demagogos.

No contexto do que estou abordado, poder-se-ia acentuar que tais espaços seriam lugares desencadeadores de um processo civilizatório de subjetividades e representações no interior dos grupos populares e onde mazelas do passado e dos laços sociais delas decorrentes para a vida urbana seriam suplantado pelo futuro tornado presente. ${ }^{13}$ Para se pensar este processo de remitologização da cidade grega no âmbito das formas de sociação propostas pelo OP, e suas derivações míticas segundo o viés judaico-cristão da terra prometida que inspirou a fundação do complexo civilizacional ibérico-europeu nos Trópicos vale acentuar alguns tópicos de atualização deste potencial mítico que a idéia de espaço publico representa para o campo das praticas da gestão participativa para o caso de Porto Alegre.

O OP carrega consigo, portanto, a utopia de um processo gestionário do poder no âmbito da complexidade das formas de vida social que as cidades brasileiras concentram, nos dias atuais, projetando-se para suas esferas de decisões a possibilidade de configurar tais centros urbanos em lugar de estabilidade, equilibro e harmonia social, desde a sua conformação como arenas politicas (espaços de deliberação e informações institucionais e institucionalizadas dos poderes públicos), embrião, desde sua força normativa, de novas praticas discursivas e praticas sociais seriam promovidas, conduzindo a comunidade urbana na direção do bem comum.

Em contraposição, o OP não atribui aos espaços informais de sociação como bares, rodas de samba, conversas de portão, quitandas, feiras, armazéns e padarias, praças e passeios públicos, esquinas e calçadas, etc. qualquer dimensão de representação social., de educação e informação politica essenciais a sua comunidade urbana. Ao contrario, e voltando-se às costas a esta dimensão do espaço publico que orientam o mito da ágora para as cidades no Ocidente moderno, a cidade segundo as formas de sociação ${ }^{14}$ propostas pelo

\footnotetext{
${ }^{13}$ A Op se organiza a partir de 03 instância básica de organização das formas de sociação, revelando uma forma de pirâmide institucional Assembléias - regionais e temáticas; o Fórum de delegados e o Conselho Municipal do OP (COP), prevendo relações hierárquicas entre seus membros participantes, onde em principio os laços e vínculos sociativos horizontais não teria espaço para se expressarem ( veremos como esta forma será polemizada por outra forma, a dos laços de solidariedade, de vizinhança, de apadrinhamento, etc.). O OP tem um regulamento que define, por sua vez, as regras de participação da "sociedade civil" e do governo municipal.. Finalmente o OP para por em pauta a sua agenda tem um calendário a ser cumprido previamente estruturado. Em termos de receitas, o OP não tem poder algum de decisão, pois esta é da esfera do executivo e legislativo.

${ }^{14}$ A participação no processo do OP não se limita ao momento da votação, trata-se de um aprendizado que ocorre desde a implementação de propostas, ao seu monitoramento e execução. A idéia é incluir os habitantes de menor poder aquisitivo e político, decorrentes de "diferenças culturais e sociais" (Marqueti \& Campos, 2008: 16) ainda que tais "diferenças culturais e sociais" sejam mencionadas elas são reduzidas às diferenças econômicas.
} 
Orçamento Participativo (OP) e seu modelo de gestão para vida urbana porto-alegrense nos últimos 20 anos (conselhos, associações, assembléias temáticas e regionais, fóruns e redes $^{15}$ ) se organizaria desde tais lugares, denominadas de arenas politicas. De tais arenas políticas propagaria, assim, uma certa matéria para o estar-junto coletivo dos grupos populares, através das quais eles iriam adquiririam força a ponto de se perpetuarem como consciência-de-si (comunidades populares) em relação aos outros segmentos sociais.

Reconheço aqui um processo dramático de tentativas por parte dos gestores e técnicos de homogeneização da heterogeneidades de laços e vínculos sociais no corpo da comunidade urbana porto-alegrense, na busca de se acentuar a alteridade (os pobres em oposição as elites e os ricos) no interior da identidade urbana local, numa recusa a logica contraditorial da presença de valores heterogeneizadores e homogeneizadores no âmbito dos processos formais de participação desencadeados pelo OP. A vida urbana concebida desde seus laços de vizinhança e de solidariedade, suas estórias dispares ou comuns, que aproximam e afastam as pessoas, as etnias, as classes, as idades umas nas outras, gerando formas diversas de habitar, trabalhar, apropriar-se e viver a cidade passa a ser operada, segundo os postulados da gestão participativa, no interior de espaços decisórios onde os laços formais preponderam sobre qualquer outra forma de sociação.

De outra forma, se esquece que a cidade entrelaça vizinhos e cidadãos em mundos simbólicos descontínuos e fragmentados, configurando a cidades em territórios diferenciados segundo fronteiras determinadas que muitas vezes encontram-se sobrepostas como experiências de vida urbana. Por outro lado, ignora-se a forma como são assimiladas e acomodadas no trajeto antropológico de configuração da pratica cotidiana do "cidadão comum" (les gens du peu, nos termos de P. Sansot) os postulados do individualismo moderno como forma orientadora dos arranjos sociais, em termos de processos de construção de subjetividades e das próprias representações simbólicas associadas a vida em sociedade. ${ }^{16}$

Outro aspecto relevante para se pensar são as escalas e níveis distintos que compõem a compreensão da dinâmica cultural que encerra o OP na organização dos

\footnotetext{
${ }^{15} \mathrm{O}$ funcionamento do OP obedece a um ciclo (ciclo orçamentário) na forma como ele organização o orçamento municipal, compreendido em 4 fases: preparação (definição do montante de receitas, definição de prioridades e elaboração da peça orçamentária), adoção (definição de preferências definidas em assembléias publicas, todo o cidadão tem direito a votar, organizadas por região e por temas), execução e controle.

${ }^{16}$ As razões para os limites distributivos e fracassos participativos vão desde apontar para o problema da crise fiscal, , limitando os investimentos, vontade política dos gestores, as relações entre o OP e o planejamento das cidades (planejamento participativo), poucos programas de geração de renda e emprego, pois as demandas das populações se concentram em saneamento e urbanização, saúde e educação, etc. Pouco de fala do rompimento da aliança política entre as camadas médias, governo municipal e os setores populares nos grandes centros urbanos (cidade de muros)
} 
arranjos da vida social num grande centro urbano-industrial, Ao privilegiar as escalas macrocósmicas das arenas políticas formalmente constituídas na condição de espaços públicos, tal gestão participativa tende a colocar em segundo plano o poder estruturante do sujeito - individual e coletivo - que representa os lugares informais do politico. Ou seja, as formas microcósmicas de sociação como espaços de sociabilidade onde as informações se acumulam numa especie de reservatório de novas políticas publicas e privadas, e onde se consolida um verdadeiro debate sobre a vida em coletividade, lugares públicos que são, na maioria das vezes, mais institucionalizados do que pensam nossas teorias sociológicas clássicas.

As grandes metrópoles antes de serem reduzidas apenas aos espaços circunscritos dos contatos face-a-face, onde todos se conhecem, por suas dimensões e complexidade de arranjos e trocas sociais e coletivos configuram-se como territórios e lugares onde se processam diferentes e múltiplos circuitos de informações, o que se torna um desafio para as modalidades de gestão participativa conceber a construção de um espaço publico abstrato e formal que passando por outros lugares públicos de congregação e de decisões da vida coletiva de caráter informais.

Portanto, para um antropólogo acostumado a operar com o paradigma das sociedades complexas, o modelo de participação comunitário-corporativa-co-gestionaria se tenciona com o caráter de descontinuidade, fragmentação e heterogeneidade de tais postulados nos interior dos arranjos sociais das grandes metrópoles brasileiras, em especial, tendo em vista o colonialismo presente nas representações que compartilham entre si os gestores, técnicos e políticos sobre as cidades "tropicais".

Centrando-se nas reivindicações de melhorias de infra-estrutura urbana para os territórios de vida dos segmentos mais pobres da cidade de Porto Alegre, os bairros populares acabam assimilados no ideário progressista as imagens da matéria disforme de seus territórios em termos dos serviços e equipamentos urbanos, lugares com ausência de sociabilidade, de laços e trocas sociais degradados, e quando estes ocorrem geralmente são interpretados como desencadeadores de desagregação social.

Nesta perspectiva, é que vemos os analistas do OP identificar os processos de sociação anteriores (clientelismo, movimentalismo, pragmatismo comunitário, etc.) no interior dos hábitos-ritmos (Bachelard, 1932: 69) que compõe as formas de sociação modernas propostas pelo OP para a gestão de Porto Alegre, atribuindo a tais formas a estabilidade insidiosa da matéria de um passado arcaico da sociedade brasileira no tempo 
presente. ${ }^{17}$ Trata-se aqui dos desafios de ser inverter tal. Ela se impões como fundamental, ou seja, pensar tal simbólica agenciada pelas imagens de deformidade para as formas de sociação no interior do OP nos últimos anos de gestão em Porto Alegre, é menos um efeito das perversidades que fundam a vida social de sua comunidade urbana local do que a constatação de que ela se configura como tal desde ação da simbólica do mito do fracasso e do atraso na tessitura de seus vínculos sociais.

\section{O Orçamento Participativo (OP)}

$\mathrm{Na}$ trilha da compreensão da polifonia das formas temporais para a compreensão dos caminhos e descaminhos da incorporação de uma gestão democrática e participativa nas políticas públicas dos grandes centros urbano-industriais do Brasil, elejo a forma como as imagens da estética da desordem se propagaram no interior do modelo de gestão da OP em Porto Alegre como foco de reflexão. A idéia é pensar tais imagens como laboratório de pesquisa de uma cultura urbana "tropical" em sua trajetória de desvio a propósito de uma estética da harmonia, profundamente moralista baseada nas imagens da ordem e do equilíbrio para os arranjos dos fenômenos da vida social ${ }^{18}$. Segundo S. Baierle (2007:.12), a paisagem urbana de Porto Alegre desde o OP parece dar a impressão do império da ordem pela atmosfera que dela emana: um eficiente serviço de limpeza urbana, muitas arvores, ruas pavimentadas, bom transporte coletivo, semelhante as cidades européias". O que faz o autor se perguntar: Onde estão os pobres? As favelas? Onde dorme a cidadania informal? uma vez que $30 \%$ da população de Porto Alegre é pobre e ocupa $10 \%$ do território de Porto Alegre, sendo 3/5 da população local afrodescendentes. ${ }^{19}$

Nos últimos anos Porto Alegre, como palco das práticas do OP, tem sido apontada freqüentemente como referencia para o Banco Mundial e suas políticas sociais (em comparação com a África) assim como para o setor financeiro dos grandes bancos nacionais e de agências estrangeiras em termos de um modelo de gestão de cidade. Tratase de um modelo de política pública baseado no ideário de empoderamento dos setores populares no que tange a decisões sobre seus territórios de vida urbana e que remonta aspectos centrais da institucionalização dos movimentos populares no âmbito dos poderes

\footnotetext{
${ }^{17}$ Exploramos aqui a temporalidade histórica elaborada por Sérgio Baierle, Lutas urbanas em Porto Alegre, entre revolução política e transformismo, Porto Alegre, Fundação Ford /ONG Cidade, 2007.

${ }_{18}$ A referencia explicita ao "mito da ordem" pode ser encontrada na referida obra citada acima (Sérgio Baierle, Lutas urbanas em Porto Alegre, entre revolução política e transformismo, Porto Alegre, Fundação Ford /ONG Cidade, 2007, p 13, já nas suas paginas iniciais.)

${ }^{19}$ Novamente a referencia é o estudo de Sérgio Baierle, Lutas urbanas em Porto Alegre, entre revolução política e transformismo, Porto Alegre, Fundação Ford /ONG Cidade, 2007.
} 
públicos municipais em sua luta singular por direito a moradia, saneamento básico, saúde, educação, regularização fundiária, etc.

Em termos pragmáticos o OP representaria, no Brasil, um modelo de gestão da vida urbana onde os poderes públicos se comprometem com um processo de transferência de renda para os setores mais pobres dos grandes centros metropolitanos através de descentralização de políticas urbanas (serviços urbanos - coleta de lixo, moradia, transporte publico, escolas, projetos comunitários, redes de água e esgotos) antes usualmente a cargo do Estado. Ao longo dos anos veremos, entretanto, que tais políticas urbanas passam a ser prestadas, por meio da terceirização, por organizações nãogovernamentais (associação de moradores, ongs, etc.) através de contratos com o setor publico, criando-se a partir disto outros panoramas para a gestão participativa no Brasil.

Presente a idéia da descentralização como modelo de gestão de uma cidade mais democrática e participativa, encontra-se a idéia de que as políticas publicas fizeram das cidades brasileiras o ventre devorador de vidas humanas, gerador de distorções, a exigir o sacrifício constante da sua matéria terrestre em suas promessas de redenção da alma bárbara de seus habitantes (e cujos hábitos e tradições não são nem sólidos, nem duráveis o suficiente para impedir que o "progresso" e o "desenvolvimento" mais justo se organize no seu interior). ${ }^{20}$ Urbanização de favelas, regularização fundiária, gestão dos vazios urbanos, etc. tornam-se, assim, interesses e motivações que estabelecem a dinâmica intrínseca da própria conformação das formas sociações promovidas pela OP, concentrados na organização e mobilização dos setores populares, tomando-se em conta que no Brasil de $20 \%$ a $30 \%$ destes segmentos sociais estão abaixo da linha da pobreza, morando em áreas de risco.

\section{As imagens da cidade e o sonho da emancipação social}

Em Porto Alegre, em 1988, o OP se inicia a partir do governo Olívio Dutra (PT), na esteira dos Conselhos Populares, criado na gestão de Alceu Collares (1986-1988), retomando, entretanto, a idéia de promoção de melhoria nas condições da vida urbana dos setores populares, e dos movimentos sociais dos anos $80 \mathrm{em}$ defesa dos direitos civis e direitos humanos e do processo de redemocratização do país, desde a vitória do Partido dos Trabalhadores (PT) para a Prefeitura Municipal.

\footnotetext{
${ }^{20}$ A propósito ver. Norbert Elias 1991. La société des individus. Paris, Fayard e Gilbert Durand 1979. Science de l'homme et Tradition, Paris, Berg International.
} 
A democracia-participativa e co-gestionaria na modalidade do OP surge, portanto, como promessa de re-organização da esfera da vida pública nas cidades brasileiras, dos poderes públicos e, concomitantemente, da sociedade civil a partir da idéia de repensar formas dos arranjos sociais no interior da cidade no sentido de superar a precarização das relações de trabalho e das condições de vida dos segmentos mais pobres da população urbana, tais como Porto Alegre e Recife Entretanto, na ação política do OP junto as comunidades residentes em áreas marginalizadas não se atribuía relevância ao parti pris simeliano segundo o qual as formas da social na ordem do cotidiano dos seus habitantes não costumam ter uma finalidade precípua em si mesmas.

Importante, se frisar que o OP, em termos de uma proposta progressista de gestão de cidade herda, nos anos 80, centros urbanos e industriais organizados segundo uma sociedade de consumo, movida por um processo de forte concentração de renda e de crescimento das camadas médias. Por outro lado; tais centros reúnem ao redor áreas marginalizadas onde concentram-se uma população pobre heterogênea em seus traços sociais e culturais, marcadas por fortes laços de solidariedade e vizinhança ao mesmo tempo dividida em redes internas de conflitos e tensões.

Em termos de desenho urbano o OP carrega a herança de um décor e de uma ambiência urbana e industrial submetida a um processo contínuo de destruição e recriação de territórios a partir do remanejo constante dos segmentos populares de seus locais de vida social no interior das cidades e de seu processo incessante de perifização e favelização. Em grande medida, a política urbana desencadeada pelo OP junto a tais territórios adere a visão tecnicista que, em seu viés civilizatório, considera os bairros e vilas populares não como complexos sociais e culturais próprios, segundo trajetórias e itinerários de seus habitantes em suas redes de pertença, mas como matéria disforme. Atentos as condições físicas e materiais dos territórios onde os segmentos populares se enraízam, não atribuindo importância ao seu caráter simbólico.

Desde este ponto de vista, as vilas populares afastadas da civilização pela falta de acesso aos bens de consumo e na ausência de serviços urbanos são vistas como conglomerados de lugares formados por paisagens urbanas degradas e marginalizadas. As formas de sociação de seus moradores em tais territórios na ausência de fins políticos de mobilização e participação formal, embora traga consigo o sentido dos sonhos e dos devaneios de emprego, saúde, moradia, educação melhores condições de vida, permanecem relegadas a segundo plano. 
Em Porto Alegre, o OP cria os slogans tais como "mais cidade, mais cidadania" assim como refunda os poderes públicos municipais atribuindo a eles um novo nome "administração popular"-, num ritual de batismo que marcaria o nascimento de um modelo de gestão de vida urbana através da qual se pretendia inaugurar uma nova forma de conformar os arranjos da vida social na cidade desde a incorporação dos segmentos populares nas decisões da gestão dos recursos públicos. Trata-se também de celebrar, neste momento, a morte simbólica, pelo menos das outras formas de funcionamento das políticas publicas locais, herdeiras do regime de exceção do final dos anos 60, e mesmo antes, tendo-se como referência as formas de vida social mais "modernas" conhecidas dos habitantes das grandes cidades brasileiras nas suas relações com os poderes públicos, isto é, o processo de modernização do Estado brasileiro e de suas políticas sociais a partir do compromisso populista da era Vargas (Getúlio Vargas) pautado pelo acesso dos setores populares aos direitos trabalhistas.

Neste caso, o OP pretendia-se diferente, ou seja, projetava-se como modelo de gestão da vida urbana independente das necessidades de políticas públicas de geração de empregos e de redistribuição de renda. Potencializando-se os processos de participação populares já inaugurados nos anos 80 por parte dos movimentos sociais no interior das vilas, periferias e bairros populares da cidade de Porto Alegre, a administração popular, assim autodenominada em seus primórdios, se propunha, finalmente, com seu modelo de gestão, promover o dialogo entre a sociedade civil (prioritariamente os setores de baixa renda) e os poderes públicos municipais, emanando da primeira propostas e da segunda as referidas políticas.

Desde um investimento expressivo na organização dos espaços formais de sociação dos segmentos populares, e investindo na cooptação de espaços públicos nãoformais e informais de sociação que ocorriam nos territórios de pertença destes estratos sociais, a cidade passaria a ser pensada, então, como palco não só das ações de promoção da igualdade jurídica entre os distintas classe e grupos sociais por parte dos poderes públicos municipais (civitas, no sentido pleno da palavra), mas das ações de superação das desigualdades sociais (raciais, étnicas, etc), pela via do exercício da pratica democrática e cidadã dos setores mais pobres nas grandes cidades. ${ }^{21} \mathrm{O}$ antigo ventre devorador de vidas

\footnotetext{
${ }^{21} \mathrm{O}$ uso abusivo da noção de Indivíduo já revela algo desta proposta participativa no sentido de abarcar postulados do individualismo moderno que sabemos não se disseminam da mesma forma no interior das classe sociais das modernas sociedades complexas, urbano-industriais, nem mesmo das classes trabalhadoras urbanas, em termos de "cultura política", inclusive. Pode-se perceber as dificuldades oriundas da oposição que os princípios genéricos que orientam a $\mathrm{OP}$, que contrapõem as elites econômicas e sociais (identificado por Marqueti \& Campos, 2008: 15 como schumpeteriana) e os cidadãos comuns (sic!).
} 
humanas se transformaria, assim, num lugar acolhedor cujo ar libertaria os mais fracos e menos poderosos do jugo de seus senhores, colocando-os lado a lado na mesma arena política..

Concretamente, tratava-se de construir a cidade desde uma outra feição política que viabilizaria a institucionalização dos movimentos populares no interior do aparato administrativo da prefeitura. Com isto as formas de sociação dos segmentos populares capitalizados na esfera formal de representação do OP operariam os processos da gestão dos investimentos do orçamento municipal. Na tentativa de superar estas contradições pela via da gestão participativa propunha-se, então, um modelo de gestão de cidade orientado para os espaços de participação popular que predominaria contrariamente ao que se poderia denominar de "privatização da vida social" que vinha ocorrendo com a feição empresarial das gestões municipais anteriores. Estamos adentro a polêmica das imagens anteriormente referidas neste artigo onde as formas de sociação veiculadas pelas imagens do espaço publico abstrato e formal e aquelas do espaço publico informal aparecem como possíveis de serem reduzidas uma na outra (quando não e o caso uma vez que operam com diferentes registro do imaginário irredutíveis entre si). Quando o espaço publico forma e abstrato engole as formas informais e não formais de exercício da cidadania, ele ascende a um estado superior de realização; por outro lado, quando o processo se dá ao inverso (o espaço publico abstrato e formal é engolido pela informalidade) tem-se aí uma degradação moral do sistema original previsto para a gestão democrático-participativa.

Em razão de uma preocupação purista, inspirada num dualismo radical entre as formas de sociação formais, por um lado, e informais e não formais, por outro lado, os territórios de vida urbana em Porto Alegre, segundo as intencionalidades dos atores sociais foram, assim, subdivididos em conselhos e suas lideranças articuladas em torno das rotinas, procedimentos e informações sobre as comunidades que reuniam em torno de si.

A intenção da OP (em suas imagens agressivas e polemicas em relação as outras formas de sociação e aos seus espaços públicos de aderência) se orientou portanto, no sentido de construir representações políticas no interior do aparato administrativo da prefeitura municipal a imagem e semelhança dos arranjos formais para a sociedade civil porto-alegrense. Para tratava-se de organizar esta sociedade civil no interior de suas "arenas políticas", fundando-se assim a "feição" popular da gestão urbana. Uma operação homogeneizadoras das praticas sociais dos grupos populares em seus territórios de vida, além de que descartava as distinções entre as imagens das outras formas de sociação geradas no plano da sociedade civil e aquelas reunidas em torno do aparato burocrático- 
administrativo do estado. Não estamos longe das antigas das motivações soberanas e as aspirações majestáticas do Heróis solar, colonizador e civilizador, agenciadas durante a conquista da matéria terrestre nos Trópicos, e que derma origem ao nascimento das cidades coloniais, imperiais e republicanas, agora retomadas no espaço das grandes cidades democráticas, moderno-contemporâneas. Não por acaso, esta polemica conduzirá os grupos populares a eufemizar tal processo de reinversão de suas formas tradicionais de sociação através de um procedimento de digestão das novas formas de participação do OP, a ponto de lhes conduzir a uma involução quase total ao neutralizar seus efeitos "negativos" para o caso das suas formas de sociação originais.

\section{O sonho acabou? Os dilemas do pensamento tecnicista e o retorno dos filhos} monstruosos!

Mais recentemente na analise das transformações nas ações cotidianas do OP, das distintas gestões administrativas do PT (Partido dos Trabalhadores) a sua incorporação na gestão do PPS (Partido Popular Socialista), os especialistas tem observado, não por acaso, de um refluxo na sustentação do princípio ético-político que propunha o $\mathrm{OP}$ em termos da garantia formal dos segmentos populares do acesso à cidade e à cidadania. De acrodo com alguns deles, os últimos anos do OP, em especial na gestão do PPS, centraram-se num conjunto de obras e ações de caráter mais assistencialista. Isto é, o novo "antigo" paradigma urbano baseado na decisão dos investimentos do orçamento municipal com base na participação popular acabou por adotar uma estética transformista da cidade, mais preocupada com os instrumentos de regulação urbana (filiada aos preceitos tecnocráticos) e menos centrada na complexidade das formas cotidianas de sociação comunitária que lhe davam sustentação.

O ideário do OP tornou-se "antigo", coisa do "passado", correndo até mesmo atingir a dimensão de mito ao sofrer transformações atribuídas as pressões sociais e históricas vindo do exterior do seu modelo de origem. Para os especialistas, geralmente os desvirtuamentos são atribuídos causas exteriores às formas de sociação instaurada por esta modalidade de gestão para a cidade. Ou seja, formas outras, disformes, tais como a perversidade das elites locais (empreiteiros de obras, incorporadoras imobiliárias, políticos corruptos, etc.) sempre a subverter e corromper a honestidade e ingenuidade dos setores populares, geralmente vistos como seres sociais impotentes aos poderes formalmente organizados. 
A imagem do bom selvagem, naif, para o cidadão comum retorna, e com ela a ameaça de sua uma queda moral: "um processo persistente de desigualdade pode produzir, nos grupos sociais que sofrem seus efeitos, uma cultura de aceitação de suas condições de vida", grupos sociais com "reduzido acesso a esfera publica” (sic!) (Marquetti \& Campos, 2008: 23). No plano dos "grandes negócios", nos anos que seguiram a criação do OP em Porto Alegre, assim como em outras cidades, assistimos a transformação deste modelo de gestão participativa em sistemas de contratos e de projetos que unem, em suas ações sociais, o poder público ao terceiro setor e às empresas privadas.

Segundo alguns analistas do OP, trata-se cada vez mais da gestão publica das desigualdades sociais e da pobreza, através do empoderamento de ongs e empresas sob a subvenção de agencias internacionais de financiamento, persistindo as desigualdades sociais, políticas e materiais entre os distintos habitantes da comunidade urbana portoalegrense, agora situados em regiões e macro-zonas, nos termos técnicos. O antigo lema mais cidade, mais cidadania se perde no campo das políticas publicas municipais que passa a se mover, cada vez mais, em razão do medo da desordem social através do calculo de uma desigualdade tolerável. Os segmentos populares, sempre através do terceiro setor, tornam-se cliente das políticas sociais da administração publica e tendo em vista a desigualdade sistêmica em que vive esta sempre oferecendo seu direito a cidade em troca de algum beneficio imediato.

Sob a ótica das atuais agencias internacionais de onde as políticas públicas retiram parte dos subsídios para suas políticas sociais e culturais, a gestão da pobreza nas grandes metrópoles brasileira passa a agregar assim valor aos investimentos públicos, onde antes a era o trabalho e a renda. Podem-se perceber, neste sentido, como as políticas públicas projetadas para as cidades democráticas brasileiras cresceram e se complexificaram à sombra das seduções do "sentimentalismo" moral que emana do passado distante da implantação de uma Civilização no Novo Mundo.

Entretanto, a persistência do desemprego e do trabalho informal entre os segmentos populares, mostra que do OP resultaram, hoje, dispositivos de manejo de uma população sem renda no interior dos territórios da própria cidade, nos moldes da gestão da pobreza (podendo ser pensada, nestes termos, as políticas de coleta seletiva e galpões de reciclagem tanto quanto aquelas dirigidas a sobrevivência dos catadores de papeis e dos carroceiros, geralmente políticas com orientações assistencialistas de geração de renda e emprego).

Ao longo da existência do OP em Porto Alegre, inúmeros estudos têm revelado que os executores tradicionais das políticas públicas no OP junto aos setores populares 
(lideranças comunitárias, representantes e conselheiros) obtiveram mini-ascensão no interior dos seus segmentos sociais de origem. Um modelo de gestão de cidade proposto progressivamente se transforma para os segmentos mais pobres, através do exercício de uma inteligência pratica respeitável, em um plano de negócios, opondo entre si, na ordem do cotidiano, inúmeras vezes comunidades, lideranças e suas territorialidades. As instancias de organização das políticas publicas (conselhos, fóruns, etc.) transformam-se em fontes geradoras tanto de renda para seus representantes tanto quanto de status e prestigio no campo das políticas do Estado. $\mathrm{O}$ antigo gestor social se torna agora o gestor cultural através do acesso que ele possui em relação a sua comunidade de origem às verbas das políticas públicas municipais.

Para se superar esta abordagem polemica e antagonista torna-se necessário se reconhecer que desde a ordem do vivido humano nas modernas sociedades complexas o tema da participação na gestão para o caso da configuração das grandes metrópoles implica pensá-las desde as suas formas heterogêneas de sociação e onde a sua feição plural recusa a exclusão do contraditorial e conflitual como manifestação da polis (retomando o pensamento simeliano). Considerando-se o OP um processo de organização das formas de sociação de vida coletiva num espaço publico abstrato e formal, que se consolida no espaço e no tempo, atravessa-o, obviamente, a experiência sociativa não-formais e informais dos segmentos mais pobres tecidas nas suas condições de vida nas cidades brasileiras. Tais pactos e contratos tecidos na informalidade de vínculos e laços de solidariedade entre eles de vizinhança e parentesco tem sido sempre, desde as origens das nossas cidades tropicais, eficientes e eficazes no sentido de driblar as ditas "dificuldades financeiras" para se apropriarem de seus territórios de vida. Evidentemente, na fala da esquerda, ao fugir aos desafios de se repensar o OP desde a convergência e a confluência de tais formas de sociação e seus registros particulares de imagens para a tessitura das formas participativa e cidadã (e porque não dizer, até mesmo, da importância de uma solidariedade orgânica entre ambas), é na "crise fiscal" dos municípios que vai se buscar as razões (materiais, nunca formais e simbólicas) as quais tem impedido o OP a realização de sua vocação "redistributiva" dos espaços urbanos em Porto Alegre.22 Entretanto, há ainda, nesta fala, aqueles intelectuais, muito poucos, que sabiamente atribuem parte dos fracassos mais recentes no interior desta forma de gestão democrática e participativa da vida urbana porto-alegrense a resistência tecnocrática às irracionalidades das classes

\footnotetext{
${ }^{22}$ Em especial a fala da esquerda se refere a "crise" para o caso das distorções do OP em Porto Alegre quando o governo estava sob a gestão do PT, sendo nuançada para explicar o fracasso mais recente do OP no governo que o sucedeu - ou seja, a ausência de sua "vontade política" e a "governança neoliberal".
} 
populares no sentido de que a adoção de suas reivindicações no plano da gestão da cidade implicaria na adoção a padrões urbanísticos "rebaixados", ou seja, largura de ruas, dimensão de lotes, etc. diferenciados, destruindo-se com isto o planejamento urbano na cidade como um todo (sic!) $)^{23}$ Vemos aqui algumas das manifestações do que me referi anteriormente, ou seja, a negação das formas não formais ou informais de sociação dos grupos populares (e de seus espaços públicos) através das quais o uso do lote, as sociabilidades da rua e do pátio, por exemplo, revelam-se como dimensões importantes de organização dos laços sociais familiares, de vizinhança e de parentesco, sendo através de tais formas que a vida cidadã se manifesta no interior dos espaços onde a tal "cidadania informal" habita.

\section{A cidade no tempo e a memória de suas formas de sociação ... a perspectiva da}

\section{formação histórica excludente no Brasil}

Não foi minha intenção apontar o tema da desordem e da desagregação, geralmente associada às formas de vida dos segmentos mais pobres no interior da formação do corpo coletivo no país desde a perspectiva da atuação perversa das elites econômicas e políticas instauradas no interior das instituições públicas brasileiras. Nem tampouco apontar o fracasso das instituições publicas democráticas modernas instauradas pelo pensamento de esquerda, em suas propostas de uma gestão democrática e participativa para as cidades brasileiras, desde a sua abordagem até certo ponto reducionista da estrutura das relações sócio-históricas complexas entre Estado e as formas de sociação presentes a sociedade civil no país.

Interpretada sob o angulo da etnografia da duração para o registro do imaginário das cidades tropicais, e no plano da memória coletiva das formas de sociação figuradas nos arranjos da vida urbana das grandes metrópoles brasileiras, as imagens de caos, degradação e desordem para os seus territórios marginais e marginalizados que tem servido como modelo de gestão das modernas cidades contemporâneas do pais (e que vem sustentando a implantação do OP em Porto Alegre), encontra significado especial se pensado na perspectiva de um arranjo temporal que reúne, em termos de dinâmica cultural, vibração das distopias do processo de formação do corpo coletivo no Brasil e suas relações com o seu ambiente cósmico e social.

\footnotetext{
${ }^{23}$ Ver a respeito Sérgio Baierle (2007:58), principalmente quando o autor comenta a concordância gratuita dos tecnocratas de esquerda com as demandas dos grupos populares quando iam ao encontro de sua visão elitista de cidade, tais como a pavimentação asfáltica, impermeabilizando o solo e aumentando a velocidade de veículos em áreas de moradia popular, assim como incremento das redes de coleta de esgotos, sem seu tratamento adequado!.
} 
Observados desde a lógica de uma etnografia da duração, os conjuntos urbanos no Brasil, e Porto Alegre não fogem a regra, guardam em si as marcas da agitação de um tempo do progresso não-finalizado (servidão financeira dos segmentos populares, criminalização da pobreza, concentração de renda, favelização, etc.), em suas promessas de uma igualdade jurídica para os seus habitantes, ainda que sob o manto das desigualdades sociais e econômicas, na perspectiva da disjunção entre cidadania formal e informal, e ate mesmo não formal.. O que coloca as questões da dominação e do consenso fatores que desafiam a gestão das cidades brasileiras nos termos do exercício de poder nas representações e nas intersubjetividades dos habitantes das grandes metrópoles, em sua feição civilizatória, de onde desponta obviamente o tema do colonialismo no interior do próprio ideário de progresso e desenvolvimento ocidental moderno.

Sob o plano da memória coletiva a herança monstruosa das formas de sociação dos setores pobres e de seus conjuntos urbanos são os testemunhos de uma longa duração, quase imóvel diante de uma história de conquistadores na América em suas relações perversas com a terra que os abrigou e os nutriu.

Esta evidencia é reconhecida por muitos intelectuais de esquerda que participaram da instauração do OP em Porto Alegre, os quais concluem, hoje, que a gestão comunitária oriunda do orçamento participativo implantado acabou derivado, após duas décadas, em políticas de compensação sistemática da exclusão das classes populares centradas no direito a terra no âmbito das formas vida urbana local (na área de saneamento, política habitacional, etc.). Desde a criação do Estatuto da cidade $^{24}$ (em conjunto com a criação do Ministério das cidades ${ }^{25}$, onde se destaca a figura de Olívio Dutra, primeiro prefeito do PT na gestão municipal) até mesmo os processos de regularização fundiária, através dos quais os setores populares obtinham a posse de seus lotes de terra onde haviam construído suas casas de forma irregular, tornou-se um processo recorrente de elitização dos espaços urbanos pelo repasse destes lotes a outros segmentos sociais em função da sua venda e da transferência.

\footnotetext{
${ }^{24}$ Nos termos do Estatuto da cidade, conforme expressa o Ministério das Cidades, trata-se de promover a justiça social no interior das cidades brasileira, efetivando os direitos de todos a uma vida digna nos grandes centros urbanos, através da participação e envolvimento dos diferentes grupos sociais, visando q produção do desenvolvimento urbano, a integração da população de baixa renda e a melhoria da qualidade de vida nas cidades brasileiras;

${ }^{25}$ Segundo Sérgio Baierle (2007:8) duas iniciativas do Ministério das Cidades devem provocar futuramente as formas de sociação orientadas para a gestão democrática e participativa da vida urbana: 1) revisão dos planos diretores para municípios com mais de 50.000 habitantes, visando sua adequação ao Estatuto da cidade e 2) a implantação do Fundo Nacional de Habitação de Interesse Social (FNHIS), cujo objetivo é de somar e articular recursos para ações em habitação para famílias de baixa renda.
} 
Segundo aponta S. Baierle (2007), ao longo dos últimos anos, e especialmente, segundo o autor, na passagem das gestões do PT para o PPS, os setores populares passaram a ser clientes do terceiro setor, ao invés de terem sido empoderados no interior da própria política publica local através de sua ação concreta nas decisões sobre seus territórios de vida, tal qual pretendia o modelo proposto pelo OP. Com o tempo, segundo ainda o autor, as ongs, associações e fundações atuantes como gestores aliados da administração publica municipal tornaram-se assim um empresário dos movimentos populares, cadastrando e classificando seus clientes conforme suas necessidades (programas Dono da Casa, Moradia Legal, Figue legal, etc.).

Nos termos de alguns teóricos ${ }^{26}$ as políticas sociais as experiências do OP acabaram resultando num processo de terceirização comunitária, ou filantropização da pobreza, sendo que o acesso aos benefícios das políticas sociais implantadas pela administração municipal local não se torna mais uma questão de direito, mas de benesse de algumas associações comunitárias, ongs e fundações, considerando-se que os contratos que ligam os poderes públicos a tais instituições podem ser interrompidos.

Um exemplo é o fato de que atualmente em Porto Alegre existem 4.000 moradores de rua, sendo que desde meados dos anos 90 a cidade, pelo viés do OP, no interior das políticas sociais municipais, mantinha convênios com ongs, fundações e associações filantrópicas que buscaram neutralizar os efeitos desta população sobre as formas de vida urbana através do manejo destas populações para albergues no sentido de retirá-los dos espaços das ruas, das praças e das esquinas.

Portanto, concluem alguns, apesar das vantagens materiais obtidas no uso dos investimentos públicos municipais em termos de moradia, saneamento, saúde e educação pela mobilização dos segmentos populares no interior das ações do OP, a manutenção da situação de pobreza, de miséria e de desemprego fez com que a autoria popular deriva-se para uma gestão assistencial dos segmentos populares na cidade no sentido de domesticar as possibilidades de desordem social e de conter sua expansão para outros espaços da vida metropolitana. Obviamente um processo realizado através dos recursos de agencias internacionais destinados ao terceiro setor através de contratos com a administração publica municipal.

\section{Conclusão}

${ }^{26}$ Cf. Adalmir Marquet, Geraldo A. de Campos e Roberto Pires (orgs), 2008. Democracia participativa e redistribuição: análise de experiências de orçamento participativo. São Paulo, Xamã. 
Desde o olhar de uma etnografia da duração (Eckert \& Rocha, 2000), dos estudos sobre formas de sociabilidade, itinerários dos grupos urbanos e memória coletiva em sociedades complexas, qualquer perspectiva de uma gestão democrática e participativa como modelo de dispor os arranjos da vida social nas grandes metrópoles pode ou não adquirir solidez no devir (fora de uma racionalidade formal). Tudo depende da forma como um modelo de gestão participativa, no tempo presente, consolida a experiência participativa e democrática "moderna" no interior de uma dinâmica cultural. Isto é, a participação como parte de uma experiência de vida coletiva pautada não numa seqüência linear e mecânica de instantes bem ordenado, mas como parte intrínseca de processos cotidianos de negociação da vida coletiva no interior dos territórios vividos por seus habitantes nas cidades, e isto a ponto de seus moradores lhe atribuírem uma materialidade suficientemente sólida no interior das formas de arranjo de suas vidas na ordem do cotidiano.

Neste sentido, não pode haver participação, popular ou não, que não acolha no seu interior necessariamente os distintos fluxos da experiência vivida dos seus habitantes na cidade, ganhando, assim, formas que persistem para além dos seus conteúdos de origem, num processo incansável de configuração e reconfiguração, e bem longe do que pode abarcar um modelo cartesiano de pensar a disseminação de espaços públicos participativos e democráticos, que se pensa livre do próprio motor da vida social que é o conflito e das formas de sociação heterogêneas que dele derivam na organização dos laços sociais no interior de uma grande metrópole.

Neste ponto, a estética da desordem no plano dos estudos do imaginário das cidades tropicais nos ajudam a pensar as condições temporais através da qual a experiencia da vida coletiva nos grandes centros urbanos, hoje, no Brasil, como experiência compartilhada, (partilhada com), pode se propagar a ponto de atingir sua perpetuidade como substância desde o esforço em construir-se a concordância das descontinuidades, diversidades e heterogeneidades de instantes vividos pelos habitantes das grandes sociedades urbano-industriais.

Para o caso das cidades tropicais, advogo que a consciência de si gerada por um tal corpo coletivo, instável em seus arranjos, sempre a serem feitos, desfeitos e refeitos no diaa-dia tragicamente se afastam de muitos de nossos sistemas interpretativos e discursivos clássicos que empregam usualmente para a compreensão dos fenômenos sociais e culturais que ocorrem nas cidades brasileiras, em especial quando se procura compreender as regras formais de regulação temporal do mito do progresso no seu interior. Nas cidades tropicais 
o controle simbólico do tempo se polemiza e desafia as motivações simbólicas de um tempo histórico e progressista.

No plano do imaginário, atuando na condição de sistemas descentrados e instáveis por abarcar precisamente um antagonismo de valores na pluralidade de suas tradições, inúmeras cidades brasileiras desde seu gesto fundacional resultaram do gesto de peregrinação de uma população de desterrados na busca de melhores condições de vida para si e seus descendentes. Tais segmentos sempre que exerceram pressão nas cidades tropicais obrigando-a a expandir do interior para fora de seus limites, gerando paisagens urbanas marcadas por harmonia tensional entre perímetro-fronteira-confim.

Igualmente neste ex-cesso, podemos enquadrar a situação de deformidade descrita por muitos cientistas sociais para o modelo de OP atualmente em vigor em Porto Alegre, uma vez que se constata que os canais de participação e interação sociopolíticos abertos nas gestões anteriores não resultaram concretamente em mecanismo políticos de reestruturação dos poderes públicos municipais, como era o previsto. Como apontam os comentários moralistas de alguns de seus analistas, as "antigas" formas de organização do OP na gestão pós PT, foram distorcidas e pervertidas chegando-se à banalização da gestão "democrática" em termos da estética do espetáculo. Ou seja, através da multiplicação de espaços "participativos" (fóruns, conferencias internacionais, etc.) que não se apresentam mais como espaços de organização dos setores populares, portanto, sem capacidade de mobilização e pressão. Para muitos dos analistas e militantes do "antigo" OP, a experiência participativa em Porto Alegre se transformou no usufruto de direitos consignados pelos poderes públicos aos segmentos mais pobres de sua comunidade urbana.

A sociologia das formas de G. Simmel (1981), afirma que qualquer fenômeno da ordem da cultura possui uma manifestação concreta e precisa que é a sua "forma" captada na exterioridade de um arranjo. Com este autor, posso me atrever a pensar que no coração das transformações de desmobilização e despolitização que se operaram no "antigo" e novo modelo de gestão do OP, na última década,se pode sempre reconhecer a rítmica do ciclo de mutilações e renascimento das formas de vida social dos segmentos mais pobres da população urbana, as quais que deram origem a implantação do conjunto civilizacional das cidades no Brasil, eternamente seduzida pela tentação das aspirações purificadoras e monárquicas do Herói civilizador nos Trópicos.

\section{Referências}


MARQUETTI, Adalmir et alli (orgs.) 2008. Democracia participativa e redistribuição: análise de experiências de orçamento participativo. São Paulo, Xamã, 2008.

ROCHA, Ana Luiza C. da "A irracionalidade do belo e a estética urbana no Brasil" In: (orgs) Z. Mesquita e C. R. Brandão, Territórios do cotidiano, uma introdução a novos olhares e experiências Ed. UFRGS/UNISC, POA/Santa Cruz do Sul, 1995.

ECKERT, Cornelia \& ROCHA, Ana Luiza C. da. Imagens do tempo nos meandros da memória: por uma etnografia da duração. In: Koury, Mauro (org.). Imagem e Memória: Estudos em Antropologia Visual. Rio de Janeiro, Garamond, 2000, pp. 19-39.

BACHELARD, Gaston L'intuition de l'instant. Paris, Denöel Gonthier, 1932.

BACHELARD, Gaston La dialectique de la durée. Paris, PUF, 1989.

SIMMEL, Georg Sociologie et Epistémologie. Paris, PUF., 1981.

SIMMEL, Georg Questões fundamentais da sociologia. RJ, Jorge Zahar, 2006..

DURAND, Gilbert Science de l'homme et Tradition, Paris, Berg International, 1979.

ELIAS, Nobert La société des individus. Paris, Fayard, 1991.

BAIERLE, Sergio Lutas urbanas em Porto Alegre, entre revolução política e o transformismo. Cidade-Centro de Assessoria e Estudos Urbanos, Porto Alegre. 2007. 